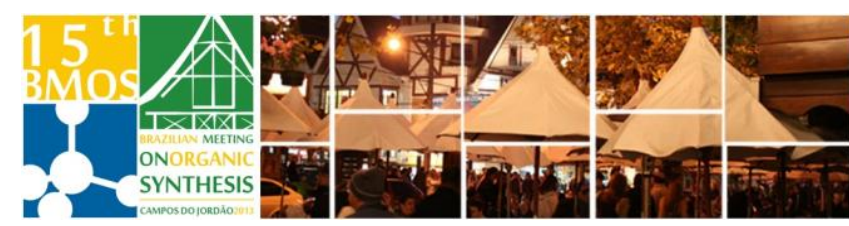

\title{
Investigation of proline derivatives for the efficient organocatalysis of an Aldol type reaction in supercritical $\mathrm{CO}_{2}$
}

\author{
R. F. Cassaro ${ }^{a^{*}}$, G. Sakae ${ }^{a}$, L.M. Takata, A. dos Santos ${ }^{a}$, R. A. Garianib and R. C. Bazito \\ a Instituto de Química - Universidade de São Paulo (USP), São Paulo, SP, Brazil

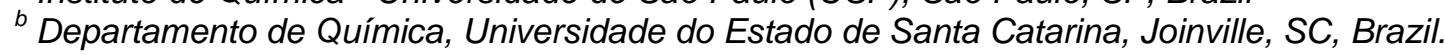

*e-mail corresponding author: rafaelcassaro@usp.br

Keywords: Aldol, Organocatalysis, Supercritical $\mathrm{CO}_{2}$

\section{INTRODUCTION}

The search for organocatalysts, i.e., small chiral molecules that are able to act as catalysts in enantioselective transformations, has received extensive attention, because of the potential for savings in cost, time and energy, easier experimental procedures, and reductions in chemical waste. ${ }^{1}$ The aldol reaction is one of the most widely used reactions for $C-C$ bond formation yet it has several drawbacks from an environmental standpoint, and this makes it an ideal candidate for organocatalysis. ${ }^{2}$

The use of supercritical carbon dioxide $\left(\mathrm{sc}-\mathrm{CO}_{2}\right)$ as a solvent for this reaction has been investigated. ${ }^{3}$ $\mathrm{Sc}-\mathrm{CO}_{2}$, is considered an environmentally benign solvent with an accessible critical point $\left(T_{c}=304.2\right.$ $K, \quad P_{c}=7.38 \mathrm{MPa}$ ), and excellent transport properties. ${ }^{4}$

Our group has recently studied a series of proline derivatives for the organocatalysis of Aldol type reactions in $\mathrm{SC}-\mathrm{CO}_{2}{ }^{5}$ In this work, we continue this investigation using proline, a proline based helical polymer and a silane proline derivative to study the behavior of a model Aldol reaction using a cyclic ketone in sc- $\mathrm{CO}_{2}$ (Scheme 1).

Scheme 1. Aldol model reaction and catalysts employed in this study.

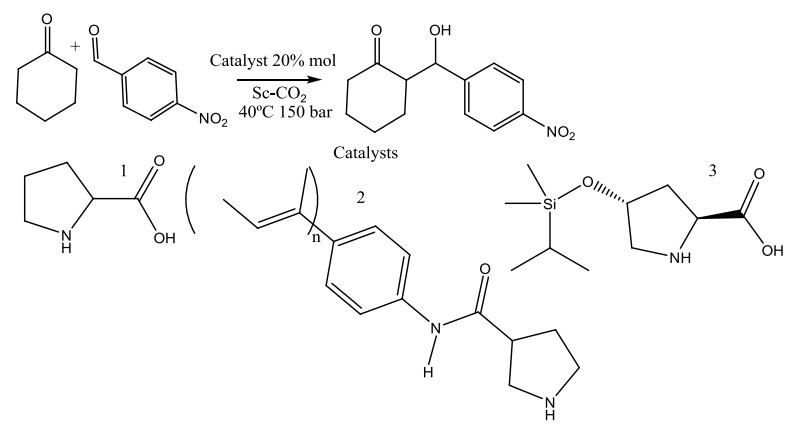

\section{RESULTS AND DISCUSSION}

The influence of reaction time and the presence of additives (acetic acid or ionic exchange resin) were investigated. The results are present in Table 1. The anti addition product was predominant in all cases. Catalyts 2 and 3 were more effective than proline (Catalyst 1), resulting in higher yields and enantiomeric excesses in shorter times. The best results were obtained with catalyst 3, using ion exchange resin, with an isolated yield of $71 \%$ and an e.e. of $91 \%$ (for the anti product - Entry 16, Table 1).

Table 1: Aldol reaction results in $\mathrm{Sc}-\mathrm{CO}_{2}$

\begin{tabular}{ccccccc}
\hline Entry & Cat. & Addit. $^{*}$ & $\mathbf{t}$ (h) & $\begin{array}{c}\text { Yield } \\
\text { (\%) }\end{array}$ & anti:syn & $\begin{array}{c}\text { e.e. anti } \\
\text { (syn) }\end{array}$ \\
\hline 1 & & $A c O H$ & 24 & 28 & $80: 20$ & $95(44)$ \\
2 & & $A c O H$ & 6 & 41 & $69: 31$ & $75(3)$ \\
3 & $\mathbf{1}$ & - & 24 & 0 & - & - \\
4 & & $A c O H$ & 48 & 28 & - & - \\
5 & & $A c O H$ & 24 & 51 & $71: 29$ & $93(21)$ \\
6 & & $R e s i n^{* *}$ & 24 & 23 & $80: 20$ & $84(15)$ \\
\hline 7 & & - & 24 & 19 & - & - \\
8 & & $A c O H$ & 24 & 97 & - & $63(-)$ \\
9 & \multirow{2}{*}{$\mathbf{2}$} & $A c O H$ & 2 & 42 & $84: 16$ & $83(7)$ \\
10 & & $A c O H$ & 6 & 63 & $74: 26$ & $90(18)$ \\
11 & & $A c O H$ & 6 & 63 & $81: 19$ & $98(6)$ \\
\hline 12 & & $A c O H$ & 24 & 27 & $79: 21$ & $89(7)$ \\
13 & & - & 24 & 42 & $86: 14$ & $84(26)$ \\
14 & \multirow{2}{*}{3} & - & 6 & 58 & $90: 10$ & $88(31)$ \\
15 & & - & 2 & 52 & $92: 8$ & $86(35)$ \\
16 & & $R e s i n^{* *}$ & 2 & 71 & $80: 20$ & $91(13)$ \\
\hline
\end{tabular}

${ }^{*} 20 \% \mathrm{~mol}$

** Ion exchange resin Amberlit IRA

\section{CONCLUSION}

Proline derivatives 2 and 3 were effective organocatalysts for the aldol reaction in $\mathrm{sC}-\mathrm{CO}_{2}$ studied in this work. Catalyst 3, however, showed a higher efficiency, resulting in higher yields and e.e. excesses in shorter times.

\section{ACKNOWLEDGEMENTS}

FAPESP, CNPq, CAPES and INCT de Estudos do Meio Ambiente for financial support and fellowships.

\section{REFERENCES}

Xiangkai Fu et al. Tetrahedron: Asymmetry 22 (2011) p.840 850.

Stevens, J. G.; Bourne, R. A.; Poliakoff, M.. Green Chem. 11 (2009), p.409-416.

Ling, L. et al. Sci. China Chem. 53 (2010) p. 1586-1591.

Kawanami, H.; et al. Chem. Commun. (2003) p.2502-2503.

Cassaro, R., de Oliveira, L., Gariani, R., et al. (2013). Green Process. Synth. 2 (2013), p. 43-50.

$15^{\text {th }}$ Brazilian Meeting on Organic Synthesis - 15 $5^{\text {th }}$ BMOS - November 10-13, 2013 - Campos do Jordão, Brazil 